\title{
MEMBANGUN KEPEMIMPINAN YANG MENYENANGKAN
}

\author{
Asep Suryana, Dr., M.Pd. \\ Jurusan Administrasi Pendidikan FIP UPI doef@upi.edu
}

\begin{abstract}
Leadership is the ability to drive, steer, even forcing people to move towards achieving the goal. Leaders hip much to appear in a variety of styles, the style is in the form of behavior that appear to form a task orientation, human relations, s piritual, social, democratic, authoritarian and others. The problem, whether theleadership ditampilkannyacukup deemed satisfactory and enjoyable for all orang.Kepemipinan unpleasant to have the possibility of moving in together all components in the organization became minimal.Menyenangkan quite perceptional, has a sense of fun that vary depending on the point where the interaction takes place.

However, there is one corner of the realignment that leaders hip must be able to foster a sense of security, certainty on the job, the assuredness of life, and improving the quality of work. The construction, arrangement must be made through the "real performance" with "personal performance", which is done by what is owned.

Des onan sibetween real with pers onal performance led to es tablish what is seen with what is in the inconsistent progress, and its resonance will look at the interaction, awkward, tense, stiff, formal dominate, less flexible bias.
\end{abstract}

Keywords; Real Performance, Pers onal Performance, Res onance, Des onansi, Fun

\section{PENDAHULUAN}

Pemimpin yang baik adalah pemimpin yang mampu bertahan dalam keterpurukan sekalipun organisasi yang dipimpinnya, ketika organisasi berada pada titik terendah maka pemimpin yang baik memposisikan sebagai alat organisasi yang memberikan ketenangan, motivasi untuk bangkit dan plindung dari ketakutan anggotanya.

Persaingan dalam organisasi meperkuat kepemimpinanya untuk tidak membawa perasaan destruktif tentang seseorang atau sekelompok orang yang berupaya untuk menjatuhkannya. Kesalahan itu akan memperkecil arti keberadaan bawahan yang merupakan teman dalam pekerjaan menjadi lawan dalam pekerjaan. Prestasi diartikan menjadi percobaan untuk menjadi saingan dalam kepemimpinanya.

Dikatakan dalam Buku Value Based Leadership oleh Asep Suryana (2012: 12) bahwa pemimpin pendidikan itu memiliki makna sebagai berikut.

$\begin{array}{lrr}\text { A Leader adalah } & \text { seorang } \\ \text { yang dipandang } & \text { memiliki } \\ \text { kelebihan dari yang } & \text { lainnya } \\ \text { untuk jangka } & \text { panjang } \\ \text { maupun jangka } & \text { pendek } \\ \text { dengan kewenangan } & \text { dan } \\ \text { kekuasan dalam } & \text { situasi } \\ \text { tertentu.Leading } & \text { adalah } \\ \text { kegiatan dimana } & \text { individu- } \\ \text { individu atau } & \text { kelompok } \\ \text { dipandang oleh satu atau } \\ \text { lainnya untuk mengarahkan } \\ \text { dalam pencapaian } & \text { tujuan, } \\ \text { walaupun tujuan } & \text { itu } \\ \text { merupakan } & \text { tujuan }\end{array}$




\begin{abstract}
individu.Dalam konteks memimpin ini banyak diantaranya anggota dari luar organisasi menjadi orang yang mengarahkan kegiatan orang yang ada dalam organisasi (bias kepemimpinan).Leadership

adalah proses yang mengarahkan kemampuan dalam pencapaian tujuan dengan memanfaatkan orangorang atau kelompok dalam kondisi tertentu.
\end{abstract}

Oleh karenanya, pemimpin bukan untuk diajak untuk memaksa biasanya lebih berat untuk mengikutinya dibanding dengan terpaksa melakukan sesuatu karena dipaksa, akan tetapi keduanya tidak akan muncul kesadaran dalam melakukan pekerjaan, pada akhirnya bekerja tanpa komitmen, atau diajak melakukan sesuatu karena sebetulnya menyukai pekerjaan itu, atau dipaksa melakukan sesuatu karena tuntutan tugas, tuntutan kehidupan tidak sama ringannya dengan terpaksa untuk dipaksa. Iklim tidak menyenangkan akan terbangun dan organisasi akan berjalan pelan seperti biasanya tanpa inovasi dan daya kreativitas untuk mencapai tujuan

\section{MEMBANGUN HUBUNGAN YANG MENYENANGKAN}

$\begin{array}{ccc}\text { Atasan dalam } & \text { organisasi } \\ \text { terjadi karena ada struktur, }\end{array}$ kewenangan memunculkan istilah siapa atasan dan siapa bawahan.Hubungan atasan dengan bawahan dibatasi oleh kewenangan, tugas pokok masing-masing dan fungsinya kewenangan untuk memerintah dan diperintah.

Hubungan yang baik dibangun dalam pola kedekatan yang mengerti batas-batas masing-masing fungsi, fungsi kehidupan memposisikan setiap orang dalam peranannya di dalam kehidupan, fungsi dalam organisasi memposisikan setiap orang dalam peranannya sebagai anggota organisasi yang memiliki tujuan bersama. Asep Suryana menegaskan (2012:25);

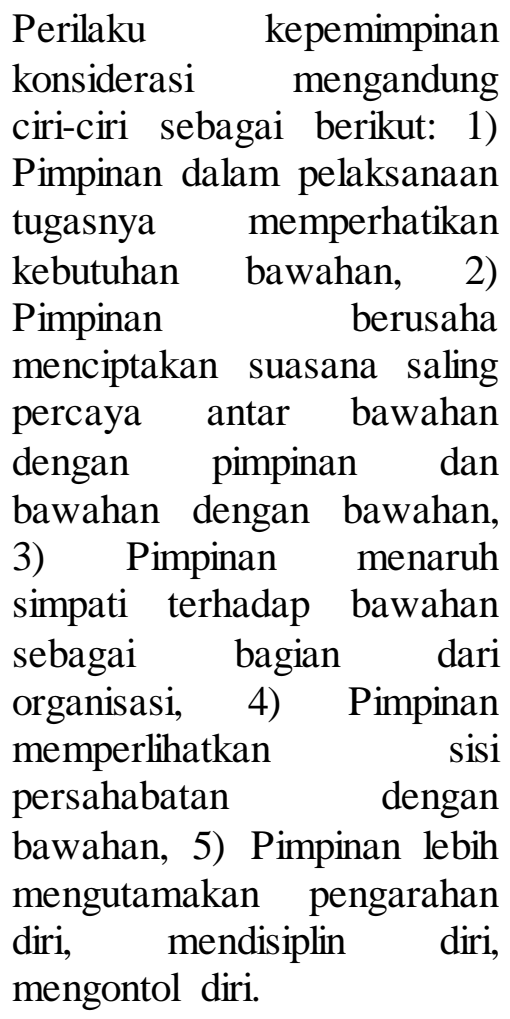

Kemasan hubungan kearah tujuan, secara formal ada dalam struktur organisasi.Struktur membatasi peranan manusia menjadi anggota organisasi, hubungan dalam organisasi dibatasi oleh tugas dan tanggungjawab.Secara informal ada jalur alterntif dalam hubungan dalam organisasi dan tidak dapat 


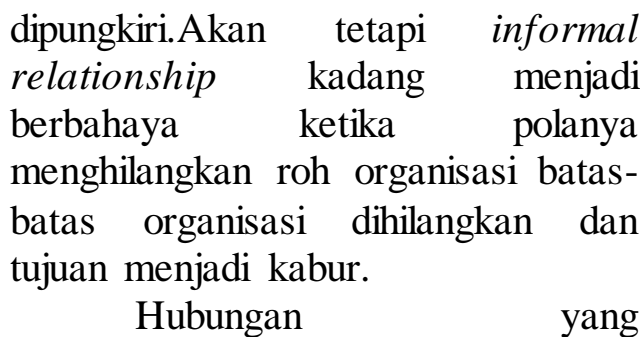
menyenangkan dalam organisasi, dibangun melalui pola-pola pembangunan iklim organisasi. Iklim yang menyenangkan tidak bisa dipaksakan kepada setiap orang akan tetapi harus dipasilitasi oleh budaya organisasi.Dalam keluarga tugas dan tanggungjawab melekat pada setiap peranan massing-masing fungsi ayah, ibu, anak, adik, kakak, kakek, nenek, bibi, paman dan lainlain.Peranan itu memposisikan masing-masing sesuai dengan tugas dan fungsinya dalam keuarga.

Bangunan organisasi adalah sekumpulan orang-orang yang memiliki hubungan, bangunan formal dalam bentuk hubungan pekerjaan, bangunan in formal dalam bentuk hubungan kemanusiaan. Peranan formal tidak bias lepas dari hubungan in-formal. Hubungan informal dapat menentukan besaran baik buruknya hubungan formal. Pekerjaan dapat diselesaikan atau tidak akan bergantung juga bagaimana iklim dibangun, iklim pekerjaan yang menyenangkan dapat muncul dari sebuah hubungan in formal yang mengedepankan aspek keterikatan setiap orang dalam satu bentukan keluarga.

\section{MERUBAH ATASAN MENJADI TEMAN}

Job Desciption atau deskripsi pekerjaan menempatkan orang pada tugas dan tanggungjawabnya masing-masing, di dalamnya dapat dilihat juga dengan siapa dan kepada siapa tanggungjawab itu melekat.

Tanggungjawab adalah pertanggungan atas sesuatu yang dipegang, oleh karenanya dalam pekerjaan sering mebawa orang menjadi kaku, kekakuan itu karena hubungan yang terjadi karena interaksi pekerjaan.Pekerjaan membawa hubungan dua orang ke dalam suatu yang formal, hubungan yang memposisikan atasan dengan bawahan.Hubungan atasan dengan bawahan ini sering terbawa ke dalam suatu situasi yang tidak formal sehingga komunikasi sering terhambat.

Pertanyaannya, untuk suatu pencapaian tujuan organisasi mungkinkah bahwa hubungan yang dibangun dalam bentuk komunikasi yang tidak formal sehingga efektivitas komunikasi bisa meningkatkan efektivitas dalam pencapaian organisasi?Saya kira dalam setting komunikasi memungkinkan bahwa hubungan pekerjaan dibangun dalam iklim yang menyenangkan dengan bungabunga persahabatan.

Persahabatan tidak terbatas dalam pergaulan secara umum dalam kontek persahabatan dua orang hal ini dapat dibawa ke dalam suatu situasi yang formal, layaknya dua sejoli yang masuk kedalam kehidupan keluarga pernikahan.Efektivitas pencapaian tujuan dapat dibuka dalam bentuk komunikasi yang lebih terbuka yang dalam perannya tetap pada masingmasing posisi.

Membangun persahabatan dalam organisasi tanpa mengabaikan aturan menagakomodasi nilai-nilai 
eksternal yang dibawa anggota organisasi kearah pemabangunan budaya, Edgar $H$ Schein dalam bukunya Organization Culture and Leadership (2004 : 3) mengatakan sebagai berikut.

a pattern of shared basic
assumptions that was learned
by a group as it solved its
problems of external
adaptation and internal
integration, that has worked
well enough to be considered
valid and, therefore, to be
taught to new members as the
correctway to perceive, think,
and feel in relation to those
problems.

Keterbukaan sebagai teman dapat membawa seseorang lebih bisa menerima kekuarangan dan kelebihannya, dapat memposisikan dalam penerimaan yang tulus tentang apapun yang muncul dalam pergaulan pekerjaan.

Peranan sebagai atasan tidak dapat digantikan menjadi peranan pertemanan dalam konteks formal, hal itu akan melekat. Akan tetapi kehidupan ini tidak hanya terjadi di dalam pekerjaan, di dalam organisasi, atau hanya di dalam kantor saja. Bahwa, hubungan orang akan meluas sampai pada kehidupan masyarakat. Joele K Jay (2009:162) dalam bukunya The Inner Edge mengatakan;

Building your team is the seventh practice of personal leadership. Building your team means identifying the people in your life who are smart, experienced,insightful, perceptive, challenging, and inspirational, and then askingthem to support you in your success.

Oleh karena itu pimpinan harus memiliki kemampuan stratejik, seorang stratejik officer memiliki tanggungjawab sebagai berikut: a) harus mampu menjabarkan strategi organisasi dalam setiap bidang pekerjaan kepada semua karyawan, mitra kerja, pelanggan, investor sehingga mereka paham terhadap rencana strategi organisasi yang mengarah kepada pencapaian tujuan organisasi, b) mendorong hasil-hasil jangka pendek untuk pencapaian tujuan jangka panjang, artinya bertanggungjawab dalam pencapaian tujuan jangka panjang dan perwujudan visi organisasi, c) melakukan pengambilan keputusan yang mendorong perubahan dalam organisasi. Dengan demikian, seorang pemimpin dengan peran sebagai eksekutif dalam organisasi harus memiliki peran-peran tersebut.

\section{MEMBANGUN KOMUNIKASI DENGAN KETERBUKAAN}

Struktur pekerjaan sudah jelas, waktu penyelesaian sudah ada, tahapan pelaksanaan pekerjaan sudah tersedia, apa lagi yang salah sehingga ketenangan menjadi terusik. Bukan atau kalau pekerjaan itu dilaksanakan sesuai dengan apa yang ada diatas tidak akan membuat menjadi tidak tenang. Ya, karena jadwal pelaksanaan pekerjaan tidak dihiraukan waktu penyelesaian menjadi mepet, karena petunjuk pelaksanaan tidak diperhatikan pengulangan dan kesalahan kerap 
terjadi, dan karena menganggap mudah pekerjaan hasil menjadi tidak maksimal.

Banyangkan, bila seorang pemimpin berlaku seperti itu apa jadinya bawahan anda, yakin mereka tidak akan tenang dalam bekerja. Hampir semua pekerjaan dapat kita lakukan, keterbatasan untuk tidak melakukan pekerjaan sebenarnya ketika kita membatasi bahwa itu tidak bisa kita lakukan.Memilih adalah pekerjaan menentukan sesuatu atas sesuatu, memilih bisa menyenangkan tetapi juga bisa berat.

Mempelajari proses

komunikasi adalah penting bagi pimpinan, karena komunikasi adalah titik koordinat, nasehat, proses evaluasi, dan bahkan supervisi melalui proses yang ditempuh.

Komunikasi adalah rantai tentang pemahaman yang bermanfaat dalam mengintegrasikan anggota organisasi dari atas sampai ke bawah, dari bawahan sampai kepada pimpinan, dan antar sisi dengan sisi secara horizontal bahkan diagonal sekalipun.

Keberhasilan penyampaian pesan oleh seorang pemimpin banyak dipengaruhi oleh berbagai hal, seperti dikatakan oleh Freeman Teague, Jr.(2008) "Nothing is so simple that it cannot be misunderstood".

Semua hal yang menghambat dalam pemahaman pesan itu adalah suatu hambatan komunikasi. Banyak penghalang-penghalang baik secara psikologis maupun fisik seperti berikut ini:

- Kultur, latar belakang, dan penyimpangan.

- Suara gaduh peralatan atau suara gaduh lingkungan akan menghalangi komunikasi yang jelas dan bersih.

- Diri kita sendiri.

- Persepsi.

lebih $\begin{gathered}\text { Tanggungjawab atas pilihan } \\ \text { berarti untuk kita }\end{gathered}$ pertanggungjawabkan ketimbang ketika kita tidak memilih salah satu diantaranya, pertanggungjawaban atas pilihan dalam pekerjaan adalah pilihan untuk baik.Permintaan maaf cukup ampuh untuk membayar sebuah kesalahan, akan tetapi harus disadari cukup sampai disana atau harus diteruskan dengan tindakan yang terlihat sebagai perbaikan. Meminta maaf jauh lebih baik dibandingkan dengan ketidakmampuan untuk menyadari telah berbuat kesalahan.

Pimpinan yang tidak pernah merasa bersalah adalah pemimpin yang mempersiapkan lubang kuburannya sendiri. Pemimpin harus memiliki keterampilan untuk menyadari kesalahan yang dilakukannya, kemampuan itu akansebanding dengan kepercayaan yang diberikan oleh bawahannya, layaknya korosi yang menggerogoti besi, maka ketika tidak merasa bersalah pemimpin sedang menegerogoti kepercayaan yang diberikan oleh pengikutnya.Tingkat yang paling tinggi dari seorang pemimpin dalam kepemimpinnya adalah menjaga kepemimpinanya melalui kemampuan untuk menerima kritik dan saraan dari orang lain.

Menyenangkan kalau orang lain melakukan kesalahan, tidak merasa bersalah ketika melakukan kesalahan sama dengan melempar tanggungjawab kepada orang lain. Kesalahan muncul diakibatkan orang 
lain atau kesalahan terjadi karena ketidakmampuan kita dalam melakukan sesuatu.Atasan harus tahu mana bawahan yang salah dalam memikul wewenang, tidak harus semuanya kesalahan dipikul oleh atasan.Bahawan harus paham ketika atasan menanaggung semua persoalan karena mungkin itu akarnya adalah permasalahan yang dilakukan bukan oleh atasan.

\section{KESIMPULAN}

Ada beberapa pemikiran yang menjadi simpulan dalam memebangun kepemimpinan yang menyenangkan;

Nilai-nilai personal yang harus muncul dalam diri pimpinan dalam bentuk keseimbangan antara actual performance, (perilaku keseharian yang nampak) nilai-nilai yang melekat ketika pimpinan memperlihatkan perilakunya dalam kehidupan keseharian dalam masyarakat dan lingkungannya, dengan task performance yaitu nilainilai yang diperlihatkan ketika dirinya mekukan tugas dan fungsi dalam sebuah organisasi.

Desonansi antara actual performance dengan task performance memunculkan kesan dan pandangan yang negatif terhadap peranannya.Artinya, bahwa sikap positif dalam pekerjaan adalah gambaran sikap dalam kehidupan kesehariannya dan hal ini harus menjadi referensi bagi setiap anggotanya.

Referensi nilai konsonansi dalam pekerjaan dan keseharian akan membangun dan menjaga power/kekuasaan pimpinan. Kekuasaan yang dibangun dengan referensi yang baik akan mengarahkan satu kekuatan kepercayaan yang sama (komunikasi harmonis) terhadap apa yang diinginkan dengan tingkat kepuasan yang sama dalam menunaikan tugas dan tanggungjawab.Kekuasaan yang digunakan menggunakan banyak basis atau dasar, pimpinan perlu memiliki kemampuan untuk menggunakan dasar yang tepat apakah reward, information, referent, charisma, coercive, sebagai basis kekuasaan sehingga mampu mentransporsi sikap kerja bawahannya.

Sikap kerja yang digambarkan dengan tingkat kepuasan kerja tidak dapat dibangun oleh nilai tunggal sebagai individu tentang pembenaran atas suatu kerpercayaan, akan tetapai harus menjadi pembenaran yang kolektif bersumber dari nilai budaya organisasi (School Culture Values).

Dalam kerangka efektivitas pencapaian tujuan organisasi perlu rekonseptualisasi dari seseorang tentang nilai; pemahaman tentang arti nilai dari banyak referensi bagaimana nilai organisasi terbentuk, pemahaman tentang batasan nilainilai yang baik dan buruk dalam organisasi, pemahaman tentang bagaimana nilai-nilai etis diimplementasikan dalam situasi kehidupan organisasi yang sebenarnya, pemahaman tentang bagaimana seharusnya berperilaku dalam organisasi, dan pemahaman tentang menjadi pelaku utama perubahan dalam pengembangan nilai dalam organisasi.

Disiplin kerja yang paling tinggi adalah self-awareness, dimana disiplin kerja adalah disiplin 
diri.Membangun disiplin kerja, efektivitasnya sangat bergantung kepada pembangunan disiplin diri dengan menjadi sebuah kepemilikan.Oleh karena itu, dibutuhkan komitmen diri yang tinggi. Komitmen diri yang tinggi dapat dipahami dari tiga sudut pandang, yaitu; sudut sikap, keteguhan akan kepemilikan suatu titik keyakinan terhadap sesuatu; sudut perilaku, bentuk kontinuitas dan intensitas dari perilaku yang konsiste; sudut spiritualitas, keteguhan akan keyakinan atas sesuatu yang menyebabkan adanya sesuatu dan keberadaannya.

Kesadaran muncul karena stimulasi tertentu dan melalui proses yang terus menerus dari pengalaman tentang sesuatu yang seharusnya dilakukan, dan tingkat penerimaan diri terhadap apa yang dilakukan. Untuk sampai pada tingkat kesadaran dalam disiplin dibutuhkan alat dan proses, serta target-target pencapaiannya. Alat penyadaran diri adalah evaluasi diri, sedangkan prosesnya melalui upaya-upaya perenungan dan penghidmatan tentang apa yang terjadi dan telah dilalui. Selanjutnya apa yang ingin dicapai, kebermaknaan akan peran yang sedang dilakukan bagi diri dan orang lain atau hanya sebatas kepuasan dalam mempertahankan eksistensi.

\section{REFERENSI}

Cooper, Robert K. (2000). Executive EQ-Emotional Intelligence in Leadership and Organization.(Alih Bahasa oleh Alex Tri Kantjono Widodo; Executive EQ-
Kecerdasan Emosional dalam

Kepemimpinan dan

Organisasi).PT Gramedia

Pustaka Utama: Yakarta.

Evans, Matt H. (2006). Value Through Leadership. (tersedia dalam

http://www.midmarketplace.co m/cop/ value-basedmanagement/ featuredarticles/ plonearticlemultipage. 2006-02-

09.7872870514/plonearticle. 2006-02-09.5290738605/).

Farrow, Loventrice. (2008). The Experiences of Minority Women Leaders as Mantes in U.S. Organizations. (Journal Emerging Leadership Journeys Vol.1.Iss.2.2008. (c) 2008 School of Global Leadership \& Entrepreneurship, Regent University ISSN 1930-806X, editoreli@ regent.edu).

Garner, Eric. (2008). The Value of Values Do you know what the most important thing in your business is. (ARTICLE June 30, 2008, Management \& Leadership, http://www.trainingtime.com/n pps/story.cfm?nppage $=320$ ).

Hazlitt, Henry. (1964). The Foundation of Morality. (Alih Bahasa oleh Cuk Ananta Wijaya 2003: Dasar-dasar Moralitas). Pustaka Pelajar: Yogyakarta.

James, W. Richard. (2004). Personal Leadership: A Practical Approach for Achieving 
Individual and Organizacional Freedom. Crips Publication Inc: USA.

Jay,. K. Joelle. (2009). The Inner Edge; The 10 Practises of Personal Leadership. Oxford:England.

Kuczmarski, Susan S. And Thomas

D.

(1995).Value-Based

Leadership; Rebuilding

Employee Commitment,

Performance, \& Productivity.

Prentice Hall: New Jersey.

McCuddy, Michael K. (2009).

Fundamental Moral

Orientations: Implications For

Values Based Leadership.

(The Journal of JVBL Value

Based Leadership

http://www.valpo.edu,

Archived Issues > Volume 1 Issue $1>$ Citizen Engineers:

Leaders in Building a

Sustainable World Valparaiso University College of Business

Administration,Valparaiso,

Indiana).

Mulyana, Deddy. (2006).

Komunikasi Antarbudaya-

Panduan Berkomunikasi

dengan Orang-orang Berbeda

Budaya. PT. Remaja

Rosdakarya: Bandung.

Rivai, Veithzal. (2007). Islamic Leadership; Membangun Superleadership Melalui Kecerdasan Spiritual. Bumi Aksara; Jakarta.

Rokeach, M. (1973).The Nature of Human Values. New York: The Free Press
Schein, H. Edgar, (2004). Organization Culture and Leadership. Jossey-Bass: San Fransisco.

Suryana, Asep. (2012). Value-Based Leadership., Nurani: Bandung

Syafii M., Antonio. (2008). Muhammad SAW; The Super Leader Super Manager. Tazkia Publishing \& ProLM Center: Jakarta.

Tasmara, Toto. (2006). Spirituat Centered Leadership; Kepemimpinan Berbasis Spiritual. Gema Insani: Jakarta. 